msh-mss Mathématiques et sciences humaines

142 | Été 1998

Varia

\title{
Un indice de concordance pour l'étude comparative d'opinions sur la conjecture
}

Concordance indices for the comparative study of opinions about economic climate

Farid Beninel et Michel Grun-réhomme

\section{OpenEdition}

\section{Journals}

Édition électronique

URL : http://journals.openedition.org/msh/2761

DOI : 10.4000/msh.2761

ISSN : 1950-6821

Éditeur

Centre d'analyse et de mathématique sociales de l'EHESS

Édition imprimée

Date de publication : 1 mars 1998

ISSN : 0987-6936

\section{Référence électronique}

Farid Beninel et Michel Grun-réhomme, « Un indice de concordance pour l'étude comparative

d'opinions sur la conjecture », Mathématiques et sciences humaines [En ligne], 142 | Été 1998, mis en ligne le 10 février 2006, consulté le 23 juillet 2020. URL : http://journals.openedition.org/msh/2761

DOI : https://doi.org/10.4000/msh.2761

Ce document a été généré automatiquement le 23 juillet 2020

(c) École des hautes études en sciences sociales 


\section{Un indice de concordance pour l'étude comparative d'opinions sur la conjecture}

Concordance indices for the comparative study of opinions about economic climate

Farid Beninel et Michel Grun-réhomme

\section{RÉSUMÉS}

Un modèle stochastique d'indices d'association sur données binaires d'un panel d'enquêtes conjoncturelles est proposé dans ce travail. Ce Modèle permet de quantifier la concordances d'opinions entre deux individus et de comparer cette concordance d'une paire d'individus à l'autre. Des propriétés des indices découlant de ce modèle sont également mises en évidence.

In this paper, we propose a stochastic model of association indices based on binary date surveys. These indices calculate the opinion concordance between two individuals and allow to compare pairs. Some properties of such indices are derived.

\section{INDEX}

Thèmes : données (analyse des), préférences (agrégation des), probabilités 